\title{
Robotic surgery 2021
}

\author{
Friedrich Längle
}

In 2020, which was mainly characterized by the COVID-19 pandemic, it was possible for me to organize the Austrian surgical congress as a hybrid congress. The theme of the congress was "Man and machine-innovation with passion".

The surgical methods and techniques of operations have changed in recent years, with the aim to reduce postoperative mortality and morbidity. The past two decades were characterized by the development of new minimally invasive surgical methods and techniques. New tools were developed, cameras and video systems were adapted, so that every surgical department owns state-of-the-art devices. Nowadays laparoscopic cholecystectomy is a standard procedure, which makes it difficult to teach young colleagues the conventional procedure. On the other hand, however, the rate of laparoscopic colon procedures is only about $30 \%$.

\section{Prim. Univ.-Doz. Dr. F. Längle ( $₫)$}

Chirurgische Abteilung, Landesklinikum Wiener Neustadt, Corvinusring 3-5, 2700 Wiener Neustadt, Austria

Friedrich.Laengle@wienerneustadt.lknoe.at
A special form of minimally invasive operation is robotic surgery. This technique is a special method operating with very high precision in order to protect anatomical structures. While the robot is virtually indispensable in urological operations, its use in visceral surgery is still viewed critically. The cost-benefit calculation as well as the benefit for patients are not yet clearly defined. The financial aspect is also subject to controversy among health care institutions. To assess the present and future value of robotic systems, more randomized trials are necessary. Therefore, many open questions remain unanswered.

With this special issue, I would like to sum up present experience in the fields of oesophageal surgery, hepatic surgery, pancreatic surgery, colorectal surgery, thoracic surgery and hernia surgery. I should like to thank the authors who have contributed to this special issue.

Conflict of interest F. Längle declares that he has no competing interests.

Publisher's Note Springer Nature remains neutral with regard to jurisdictional claims in published maps and institutional affiliations. 